\title{
Antiparasitic drugs for paediatrics: systematic review, formulations, pharmacokinetics, safety, efficacy and implications for control
}

\author{
JENNIFER KEISER ${ }^{1,2}$, KATRIN INGRAM ${ }^{1,2}$ and JÜRG UTZINGER J $^{2,3}$ \\ ${ }^{1}$ Department of Medical Parasitology and Infection Biology, Swiss Tropical and Public Health Institute, P.O. Box, \\ CH-4002 Basel, Switzerland \\ ${ }^{2}$ University of Basel, P.O. Box, CH-4003 Basel, Switzerland \\ ${ }^{3}$ Department of Epidemiology and Public Health, Swiss Tropical and Public Health Institute, P.O. Box, CH-4002 Basel, \\ Switzerland
}

(Received 14 November 2010; revised 21 December 2010; accepted 22 December 2010; first published online 24 February 2011)

SUMMAR Y

Drug development for paediatric applications entails a number of challenges, such as the wide age spectrum covered - from birth to adolescence - and developmental changes in physiology during biological maturation that influence the efficacy and toxicity of drugs. Safe and efficacious antiparasitic drugs for children are of pivotal importance given the large proportion of burden attributable to parasitic diseases in this age group, and growing efforts to administer, as widely as possible, antiparasitic drugs to at-risk populations, such as infants and school-aged children, often without prior diagnosis. The purpose of this review is to investigate whether antiparasitic drugs have been adequately studied for use in paediatrics. We approached this issue through a systematic review using PubMed and the Cochrane Central Register of Trials covering a period of 10 years and 8 months until the end of August 2010 to identify trials that investigated efficacy, safety and pharmacokinetic (PK) parameters of antiparasitic drugs for paediatrics. Overall, 269 clinical drug trials and $17 \mathrm{PK}$ studies met our inclusion criteria. Antimalarial drugs were the most commonly studied medicines (82.6\%). Most trials were carried out in Africa and children aged 2-11 years were the age group most often investigated. Additionally, we critically examined available drug formulations for anthelminthics and identified a number of shortcomings that are discussed. Finally, we shed new light on current proposals to expand 'preventive chemotherapy' to preschool-aged children and emphasise that new research, including risk-benefit analyses, are needed before such a strategy can be adopted more widely.

Key words: Antiparasitic drugs, antimalarials, anthelminthics, preventive chemotherapy, paediatrics, infants, children, adolescence, systematic review, drug formulation.

\section{INTRODUCTION}

Drug development for the paediatric population is a challenging endeavour, since a wide age spectrum from birth to adolescence is covered. A useful stratification of the paediatric population is the one proposed by the World Health Organization (WHO) using the following five classes: (1) preterm newborn infants; (2) term newborn infants (0 to 28 days); (3) infants and toddlers ( $>28$ days to 23 months); (4) children (2 to 11 years); and (5) adolescents (12 to 16-18 years) (WHO, 2007a). Importantly, the developmental changes in physiology during biological maturation from newborns to adolescence influence the efficacy and toxicity of drugs. Indeed absorption, distribution, metabolism, excretion and toxicity (ADMET; see Glossary) are all age dependent. Textbooks and detailed reviews are available

\footnotetext{
* Corresponding author: Jennifer Keiser, Department of Medical Parasitology and Infection Biology, Swiss Tropical and Public Health Institute, P.O. Box, CH4002 Basel, Switzerland. Tel.: + 4161 284-8218. Fax: +4161 284-8105. E-mail: jennifer.keiser@unibas.ch
}

that summarise key factors responsible for differences in drug disposition between paediatric and adult population such as proportions of body fat, protein, extracellular water, organ size, membrane permeability, plasma proteins, enzymes, glomerular filtration or tubular secretion (Strolin Benedetti et al. 2005; Rakhmanina and van den Anker, 2009). For example, body water is decreased from $80 \%$ in newborns to $60 \%$ in 5 -month-old infants (WHO, 2007a). Moreover, absorption, stability and ionisation of drugs depend on gastric $\mathrm{pH}$, which is agedependent. In the neonatal period an elevated $\mathrm{pH}$ is observed (i.e. the $\mathrm{pH}$ is neutral rather than acidic as in adults), which explains that, in younger age groups, a greater bioavailability of acid-labile compounds occurs (e.g. penicillin) (Kearns et al. 2003).

In view of the aforementioned issues it is not surprising that the need for age-appropriate pharmacotherapy was already recognised more than 100 years ago (Kearns et al. 2003). The International Conference on Harmonisation of Technical Requirements for the Registration of Pharmaceuticals for Human Use (ICH-E-11) states that "Paediatric 
patients should be given medicines that have been appropriately evaluated for their use" (http://www. fda.gov). We pose the question whether antiparasitic drugs have been adequately evaluated prior to wider application in paediatric populations. Indeed, addressing this question served as the main motivation for the current paper, which forms part of a special issue of Parasitology pertaining to "Progress in Paediatric Parasitology" (see Stothard and Booth editorial in this special issue).

We first provide a short historical background on paediatric drug development and highlight practical, ethical and economic issues. We then juxtapose the latest United Nations (UN) population figures and disease burden estimates in the lowest income countries. To strengthen the current evidence-base of antiparasitic drugs in the paediatric population, we performed a systematic review using two readily available electronic databases. We examined the type of drugs investigated, the age of the study participants and performed a temporal and geographical analysis of studies meeting our inclusion criteria. Paediatric pharmacokinetic (PK) studies were also examined. With an emphasis on anthelminthic drugs, we critically reviewed available drug formulations. Finally, in the current era of 'preventive (anthelminthic) chemotherapy' (see Glossary), that is the regular administration of antiparasitic drugs to entire at-risk populations (WHO, 2006, 2010a), we discuss implications for control programmes that aim at including also preschool-aged children.

\section{PAEDIATRIC DRUG DEVELOPMENT}

\section{Regulatory, ethical, commercial and economic issues}

Regulatory efforts to protect children from harmful medications began in the mid- $20^{\text {th }}$ century, in response to serious adverse events, such as limb malformations caused by thalidomide (Barsch and Otte, 2010). Indeed, thalidomide (Contergan ${ }^{\circledR}$ ), which had been used as a treatment for recurring morning sickness in pregnant women during the 1950 s and the early 1960 s, caused peripheral neuritis and malformations, e.g. phocomelia, in babies of mothers who had taken thalidomide over the course of their pregnancies (Stötter, 2007; Barsch and Otte, 2010). Once the evidence of these serious adverse events of thalidomide had been established through case-control studies, the medication was withdrawn from the market (Mellin and Katzenstein, 1962). As a consequence, many drugs received marketing authorisation for use in adults only. However, an increase in off-label use (see Glossary) was subsequently observed, amounting to $80 \%$ in paediatric patients (Pandolfini and Bonati, 2005; Stötter, 2007).

Bearing the aforementioned dilemmas in mind, over the past two decades, regulations have been enacted upon and incentives created; first in the US (e.g. Food and Drug Administration Modernization Act (FDAMA) instigated in 1998 and Best Pharmaceuticals for Children Act (BPCA) put forth in 2002; see Glossary) and, second by a number of EU paediatric guidelines (Rose, 2009). The purpose of these regulations was to improve paediatric drug development, particularly in terms of safety (Schachter and Ramoni, 2007; Macleod, 2010). It is clear that these initiatives and regulations have changed the landscape for paediatric drug development. For example, there are recent signs of enhanced research activities going hand-in-hand with clinical trials on the efficacy and safety of drugs in children including PK studies and the development of drug formulations that are suitable for the paediatric population (Macleod, 2010).

Nonetheless, there are a number of challenges regarding clinical trials in children. Ethical issues include the complexity to obtain written informed consent from parents and legal guardians, as well as assents from participating children (Kuepfer and Burri, 2009). Furthermore, the level of invasiveness should be kept as little as possible, and hence the number of blood samples and the amount of blood taken in PK studies should be minimised (Howie, 2011). Scientific issues comprise, for example, the necessity to stratify the patient population into different age groups or the need to develop microassays to analyse small amounts of biological samples that are typically obtained from paediatric populations (Conroy et al. 2000; WHO, 2007a; Choonara, 2009).

Finally, there are commercial and economic issues as the market for paediatric medicines is small compared to the adult population (estimated to be less than $10 \%$ of the total prescription drug market (Milne, 2009)), and hence lacks attractiveness for the international pharmaceutical industry. While blockbusters mainly address highly prevalent chronic diseases, children often experience acute illnesses, and the chronic conditions that do exist in the paediatric population are mostly rare disorders (WHO, 2007b; Milne and Bruss, 2008).

PAEDIATRIC DRUG DEVELOPMENT, DEMOGRAPHY AND DISEASE BURDEN

In the US, since the FDAMA institutionalised an incentive of a 6 -month patent extension for previously approved drugs in July 1998, a total of 173 drugs were granted paediatric exclusivity (http://www.fda.gov/ downloads/Drugs/DevelopmentApprovalProcess/ DevelopmentResources/UCM223058.pdf). These developments, it was claimed, showed the achievements made by FDAMA for the paediatric population. However, it should be noted that most of these patent extensions were for drugs targeting the central nervous system (CNS) (e.g. anti-depressants), cardiovascular system (e.g. ACE inhibitors), alimentary tract and metabolism (e.g. anti-diabetic drugs) and 
anti-infectives (e.g. antibiotics). Indeed, a deeper analysis revealed a major discrepancy between drugs granted exclusivity and those frequently used by children (e.g. respiratory drugs, dermatologicals and anti-infectives) (Boots et al. 2007). Hence, the real needs in paediatric drug development and use have not been addressed by exclusivity rights granted by FDAMA. In contrast they were primarily driven by the adult drug market (Boots et al. 2007).

Those drugs that are currently available and are essential for children must be prioritised for paediatric development. Indeed, there is growing recognition that among essential medicines, issues of safety, access and formulations for the paediatric population are of pressing global public health relevance. This can be further underscored by juxtaposing population figures put forth by the UN (United Nations, 2009). In 2010, an estimated 2.47 billion were newborns, infants, children and adolescents below the age of 19 years. The paediatric population, therefore, currently accounts for more than a third $(35 \cdot 7 \%)$ of the world's population. Meanwhile, it has been estimated that 432.5 million children and adolescents currently live in the least developed countries, which comprise 49 countries, of which 33 are in Africa, 10 in Asia, five in Oceania and one in Latin America and the Caribbean. Compared to the total population in these 49 countries (i.e. 854 million), the paediatric population therefore accounts for more than 50\% (United Nations, 2009).

It is encouraging to note that new campaigns have been launched with the goal to expedite paediatric drug development. For example, "Make medicines child size" is a global initiative launched in December 2007 under the leadership of WHO in order "to raise awareness and accelerate action to address the need for improved availability and access to safe childspecific medicines for all children under 12” (http:// www.who.int/childmedicines/en/). High priority therapeutic areas include respiratory diseases as well as parasitic and infectious diseases. The importance of the latter group of diseases must be emphasised, which is clear when one examines global burden of disease estimates. In 2004, for example, children aged below 14 years experienced the loss of $548 \cdot 3$ million disability-adjusted life years (DALYs; see Glossary). Three-quarter of this burden (409.8 million DALYs) occurred among children from low-income countries. Infectious and parasitic diseases were responsible for more than 300 million DALYs, with $79 \%$ of this burden concentrated in low-income countries, disproportionally shared by children younger than 14 years $(58 \%)$ (WHO, 2008a). The proportion of disease burden attributable to infectious and parasitic diseases in children in low-income countries was 38\% (154.3 million DALYs) (WHO, 2008a). Moreover, infectious diseases are a leading cause of death in children younger than 5 years, particularly in lowincome countries. The latest estimates for the year
2008 suggest that among the 8.80 million deaths in children under the age of 5 years, two-third $(68 \%$ or 5.97 million deaths) were due to infectious diseases, the three most important of which were pneumonia (1.56 million deaths), diarrhoea ( 1.34 million deaths) and malaria (732,000 deaths) (Black et al. 2010). Of note, intestinal parasites are responsible for reductions in appetite, absorption, digestion and increasing intestinal nutrient losses (Lunn and Northrop-Clewes, 1993), and hence might contribute to undernutrition, which is the underlying cause of a third of deaths in children younger than 5 years (Black et al. 2010).

CLINICAL TRIALS WITH ANTIPARASITIC DRUGS FOR PAEDIATRICS

\section{Search strategy and selection criteria of a systematic review}

We were interested in clinical trials involving antiparasitic drugs in the paediatric population, as well as PK studies, covering a period of 10 years and 8 months until the end of August 2010. Previous articles highlighted the paucity of paediatric clinical trials involving children in the developing world (Sammons and Choonara, 2005; Nor Aripin et al. $2010 a, b)$. For example, in 2007, only one out of four trials were carried out in developing countries (Nor Aripin et al. 2010b). Between 1996 and 2002, a total of 99 trials carried out in the developing world were identified with a specific focus on antiparasitic and anti-infective drugs. However, no details were presented on the type of medication studied or age group involved (Nor Aripin et al. 2010a).

We performed a systematic review on PubMed (http://www.ncbi.nlm.nih.gov/pubmed/) and the Cochrane Central Register of Controlled Clinical Trials (http://onlinelibrary.wiley.com/o/cochrane/ cochrane_clcentral_articles_fs.html). In order to maximise sensitivity and specificity (Kastner et al. 2006), we used the following age-specific MeSH terms: 'child', 'adolescent' or 'infant', in combination with 'clinical trial' and 'antiparasitic agent'. For the search on PK studies, the same age-specific MeSH terms were employed, but in combination with 'pharmacokinetics'. Our searches were temporally restricted (from 2000 to the end of August 2010), while there was no language restriction. Abstracts of the retrieved publications were analysed, adhering to a standard protocol developed by the authors. Studies had to pass the following inclusion criteria: (1) study population of children or adolescents (age: $\leqslant 18$ years); (2) trials investigating drug efficacy (e.g. no vaccination or supplements); and (3) study performed on any parasitic disease. The following information was retrieved from each study that met our inclusion criteria: (i) year of publication; (ii) parasite studied; (iii) study setting and country; 


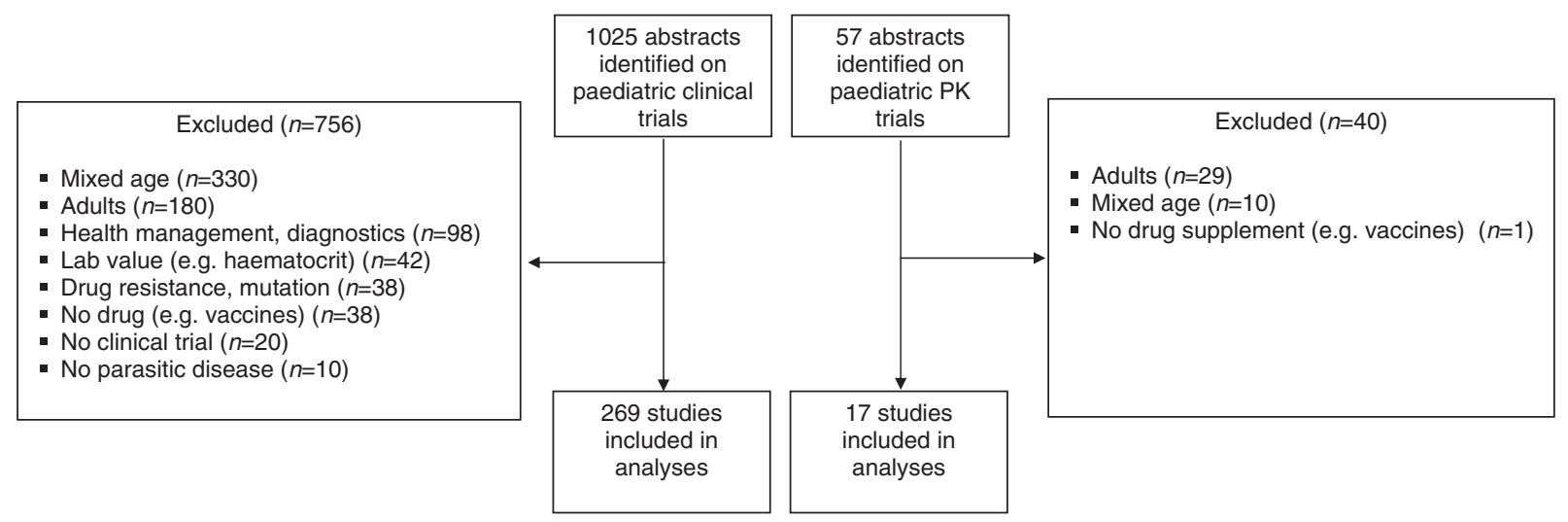

Fig. 1. Flow chart of study selection for systematic review of clinical trials and PK studies with antiparasitic drugs in children covering a period of 10 years and 8 months until the end of August 2010.

(iv) sample size; (v) age and age group of study population; (vi) methodological quality of trial; and (vii) type of medication used (e.g. substance, preparation and Anatomical Therapeutical Chemical (ATC) classification system; see Glossary).

\section{Number of studies identified and age groups}

A total of 1025 articles were identified. Based on the abstracts 756 studies were excluded and full-text copies were obtained from 269 articles. The three main reasons for exclusion were: (1) study population consisting of children and adult patients (44\%); (2) entire study population aged 18 years and above (24\%); and (3) trials investigating diagnostic tests or focusing on health management issues (13\%). Additional exclusion criteria are summarised in Fig. 1.

In four out of five trials $(80 \%)$ both infants and children (113 trials) or children only (102 trials) were included. The remaining $20 \%$ of the trials involved the following age classes: (1) children and adolescents (34 trials); (2) infants (15 trials); (3) infants, children

Table 1. Number of paediatric patients involved in clinical drug trials and pharmacokinetic (PK) studies identified through a systematic review covering a 10 -year period until the end of August 2010

\begin{tabular}{lrrrrr}
\hline \hline & \multicolumn{2}{l}{$\begin{array}{l}\text { Clinical drug } \\
\text { trials }\end{array}$} & & \multicolumn{2}{l}{ PK studies } \\
\cline { 2 - 3 } \cline { 5 - 6 } Sample size $(\mathrm{n})$ & No. & $\%$ & & No. & $\%$ \\
\hline 550 & 32 & $11 \cdot 9$ & & 11 & $64 \cdot 7$ \\
$51-100$ & 40 & $14 \cdot 9$ & & 3 & $17 \cdot 6$ \\
$101-250$ & 89 & $33 \cdot 1$ & & 2 & $11 \cdot 8$ \\
$251-500$ & 48 & $17 \cdot 8$ & & 0 & 0 \\
$501-1000$ & 32 & $11 \cdot 9$ & & 1 & $5 \cdot 9$ \\
$1001-2500$ & 26 & $9 \cdot 7$ & & 0 & 0 \\
$2501-5000$ & 2 & $0 \cdot 7$ & & 0 & 0 \\
Total & 269 & 100 & & 17 & 100 \\
\hline \hline
\end{tabular}

and adolescents (four trials); and (4) adolescents (one trial). More than $90 \%$ of the trials enrolled children (93.7\%), while only 39 trials included adolescents. The number of participants per trial ranged from 10 to 4906. One third of all trials recruited between 101 and 250 participants. Table 1 shows the frequency of trials, stratified by different sample sizes.

\section{Outcomes from temporal and geographical analyses}

Our temporal analysis revealed that the number of paediatric drug trials steadily increased between 2000 (only two trials) and 2004 (37 trials), decreased in the following 2 years (25 and 23 studies in 2005 and 2006 , respectively), and subsequently varied between 27 and 36 per year. In 2010, until the end of August 2010, a total of eight trials were identified for antiparasitic drugs in paediatrics (Fig. 2).

The studies examined were carried out in 61 countries. More than a third of the trials (38.7\%) were conducted in only five countries: Thailand (24 trials), Nigeria (21 trials), United Republic of

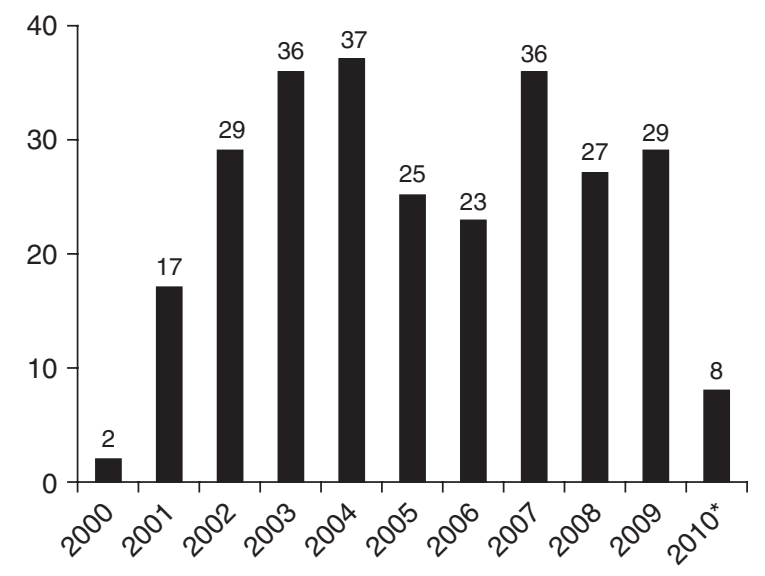

Fig. 2. Temporal analysis of paediatric drug trials identified through a systematic review covering a 10 -year period until August 2010. (* indicates that in 2010 only the first 8 months were analysed). 
Tanzania (21 trials), Uganda (20 trials) and Ghana (18 trials). Interestingly, almost three-quarter of the trials were implemented in Africa (72.7\%). The respective percentage of trials carried out in Asia, South America, North America, Australia and Europe was $16 \cdot 8 \%, 3 \cdot 6 \%, 3 \cdot 3 \%, 2 \cdot 0 \%$ and $1 \cdot 6 \%$, respectively (Fig. 3).

\section{Drugs investigated}

Ninety-three percent of the drug trials that we identified through our systematic review investigated antiparasitic medications. The remainder of the studies $(7 \%)$ examined drugs of the following ATC classes: alimentary tract and metabolism, blood and blood forming organs, dermatologicals, systemic hormonal preparations, anti-infectives for systemic use, antineoplastic and immunomodulating agents, musculo-skeletal system, CNS and respiratory system. Less than a third (29\%) of all included studies were classified as randomised controlled trials.

Fig. 4 shows that most of the antiparasitic drugs studied were antimalarials $(82 \cdot 6 \%)$, followed by therapies for gastrointestinal nematodes $(9 \cdot 8 \%)$, amoebiasis and other intestinal protozoal infections $(3 \cdot 7 \%)$, schistosomiasis $(2 \cdot 9 \%)$ and agents against leishmaniasis and trypanosomiasis $(1 \cdot 0 \%)$. A closer inspection of the drugs studied showed that sulphadoxine-pyrimethamine (SP) was the most frequently trialled medication ( $20 \%$ of all studies), which is explained by the use of SP as part of malaria control, with a strategy termed intermittent preventive therapy in infants $\left(\mathrm{IPT}_{\mathrm{i}}\right)$ and children $\left(\mathrm{IPT}_{\mathrm{c}}\right)$ (see Glossary) (Aponte et al. 2009; Gosling et al. 2010). Other frequently used antimalarials in the paediatric population identified through our systematic review were amodiaquine and artesunate (both 15\%) and chloroquine $(10 \%)$. Albendazole was the most commonly studied anthelminthic drug ( $5 \%$ of all trials).

\section{PK studies}

Fifty-seven studies were retrieved after systematically searching for PK investigations of antiparasitic drugs in paediatrics covering a period of 10 years and 8 months until the end of August 2010. Forty studies were excluded when applying our selection criteria (study participants aged $\geqslant 18$ years or studies including both adults and children $(n=39)$; one trial investigated a supplement rather than a drug).

The sample size of the 17 included studies ranged from as few as 10 individuals to 899 subjects (Table 1). Two-third of the trials $(n=11)$ recruited 10 to 50 participants, while only one trial had a sample size of more than 250 individuals. The most commonly studied age group were children: 10 trials were performed exclusively with children and five studies included both children and infants. The age

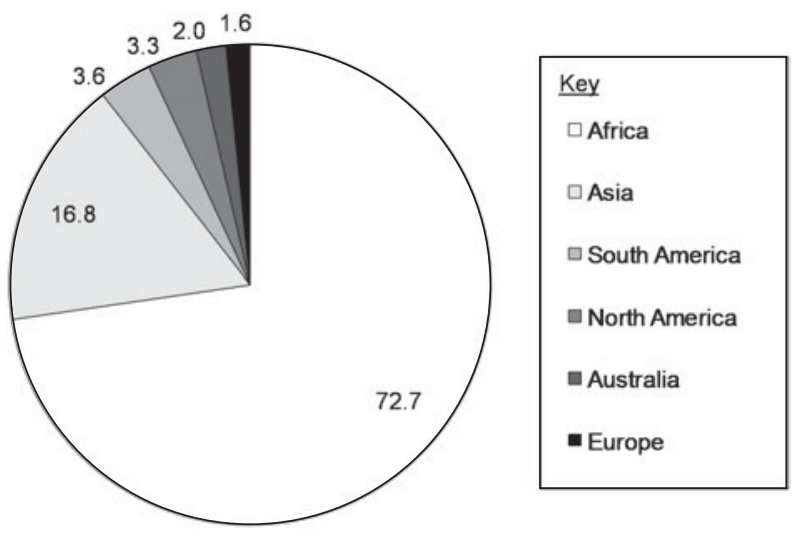

Fig. 3. Geographic location of paediatric drug trials (\%) identified through a systematic review covering a period of 10 years and 8 months until the end of August 2010.

groups of solely infants and adolescents in combination with children were only represented in a single study each. PK parameters of antimalarial drugs were studied in 15 of the 17 trials. The remaining two PK studies investigated anthelminthics and a neoplastic agent for leishmaniasis. The antimalarial drugs artesunate and quinine were investigated most often (each drug in $29 \%$ of the PK studies identified). With regard to anthelminthic drugs, albendazole and praziquantel were the only compounds subjected to PK investigations in the paediatric population.

\section{DRUG FORMULATIONS}

\section{General considerations}

Although there is a pressing need for developing new antiparasitics, very few drugs have been markedapproved in recent years. For example, while 11 new antimalarials have been marketed between 2000 and 2009 , no new drugs have been approved in any of the other parasitic disease categories over the same period (Cohen et al. 2010). Given the paucity of clinical trials in paediatrics focusing on diseases other than malaria, it is conceivable that only very few, if any, drugs for other parasitic diseases will be forthcoming in the near future. However, drugs can be considerably optimised when new drug formulations are developed (Kayser et al. 2003).

Desired criteria for drug formulations include (1) good bioavailability; (2) safe excipients and ingredients; (3) dose uniformity; (4) ease and safety of administration; and (5) socio-cultural acceptability (Breitkreutz and Boos, 2007). Based on factors such as solubility and taste of the compound formulation, development can be a time consuming and technically challenging task and the financial implications are considerable (Milne, 2009). Yet, an acceptable formulation is particularly important for children. Indeed, one of the key issues in the development of paediatric drugs is the selection of the most appropriate dosage form in relation to age. Numerous drug 


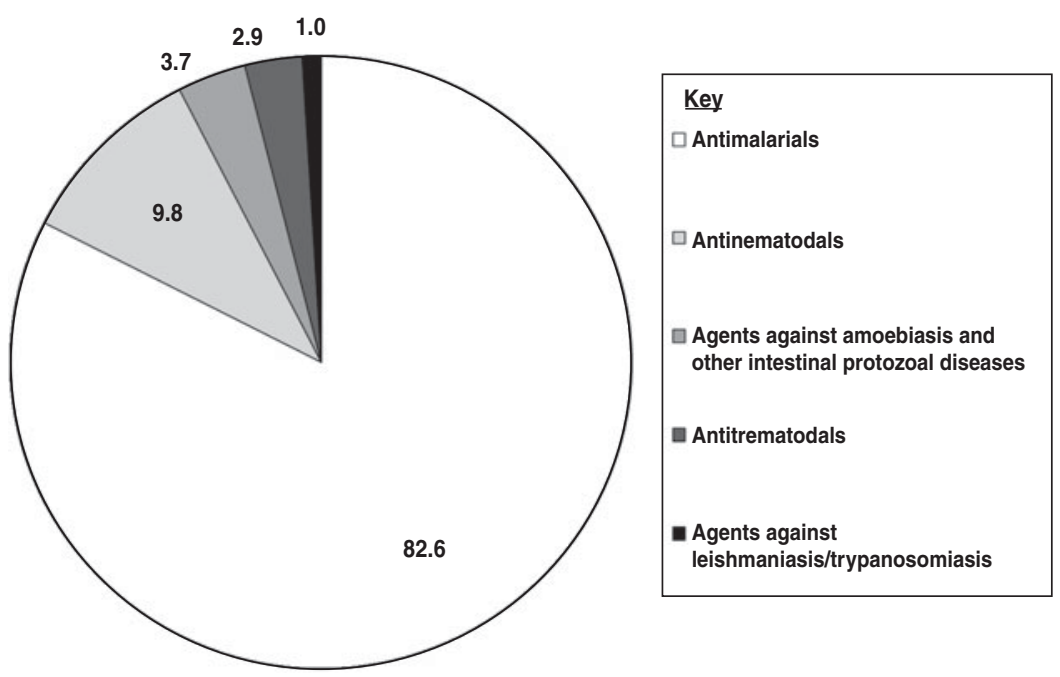

Fig. 4. Drug classes investigated (\%) in a systematic review covering a period of 10 years and 8 months until the end of August 2010.

administration routes are available, such as peroral, nasal, parenteral, topical, rectal or buccal (Breitkreutz et al. 2007). Matrixes combining different paediatric age groups, routes of administration and dosage forms have therefore been developed to assist in selecting the ideal formulation (see, for example, http://www.ema.europa.eu/docs/en_ GB/document_library/Scientific_guideline/2009/09/ WC500003782.pdf and Breitkreutz (2009)). A slightly simplified matrix for oral routes of drug administration using 'traffic light colours' is depicted in Fig. 5. Ideal, recommended and desired dosage forms are shown using green colour, less preferred but probable applicable dosage forms are marked with orange colour and not applicable oral dosage forms are depicted in red. For example, solid dosage forms might pose problems to small children as they have difficulties swallowing tablets. It follows that tablets and capsules are not recommended for infants and toddlers, and applicable but not preferred for preschool-aged children.

Clearly, oral drug administration is the predominant route in paediatric patients and different oral dosage forms (e.g. solutions, syrups, powder, granules and effervescent tablets) have been developed. However, in particular when drugs are not licensed for children (i.e. off-label use) suitable liquid forms are often not available. Inert ingredients must be selected very carefully as children might have adverse reactions to colourings, flavouring or preservatives, which are commonly used in adult formulations (Milne, 2009). Taste is a particularly crucial issue to ascertain high compliance in children. For example, a survey carried out in the US interviewing 500 parents

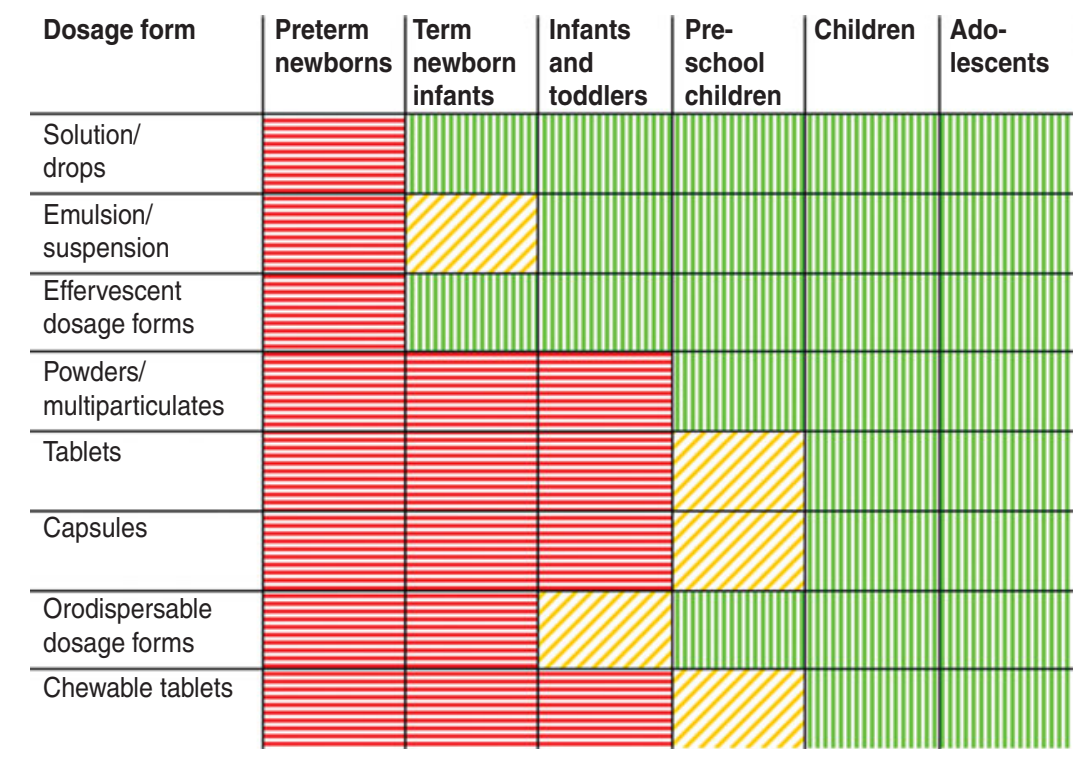

Fig. 5. Matrix combining different dosage forms for oral routes of drug administration for different paediatric age groups. 
Table 2. Available drug formulations, their producers, recommended dosages and paediatric use for drugs used for the treatment of schistosomiasis, food-borne trematodiases, soil-transmitted helminthiases and strongyloidiasis

\begin{tabular}{|c|c|c|c|c|c|}
\hline Infection & Drug & Formulation & Producer(s) & Recommended dosage & Paediatric use \\
\hline \multirow[t]{2}{*}{$\begin{array}{l}\text { Schistosomiasis } \\
\text { and food-borne } \\
\text { trematodiases }\end{array}$} & Praziquantel & $\begin{array}{l}\text { Tablet, } \\
600 \mathrm{mg}\end{array}$ & $\begin{array}{l}\text { Four large scale } \\
\text { producers: Merck, } \\
\text { Shin Poong, } \\
\text { EIPICO, Cipla }\end{array}$ & $\begin{array}{l}40 \mathrm{mg} / \mathrm{kg} \text { once } \\
\text { (schistosomiasis), } \\
\text { multiple doses } \\
\text { (schedule depending }\end{array}$ & $\begin{array}{l}\text { Experience in } \\
\text { children } \\
\text { below } 4 \text { years } \\
\text { is limited }\end{array}$ \\
\hline & Praziquantel & $\begin{array}{l}\text { Syrup, } \\
120 \mathrm{mg} / \mathrm{ml} \\
\text { (Epiquantel) }\end{array}$ & EIPICO & $\begin{array}{l}\text { on trematode; food- } \\
\text { borne trematodiases) }\end{array}$ & \\
\hline Fascioliasis & Triclabendazole & $\begin{array}{l}\text { Tablet, } \\
250 \mathrm{mg}\end{array}$ & Novartis & $\begin{array}{l}10 \mathrm{mg} / \mathrm{kg} \text { once }(20 \mathrm{mg} / \\
\mathrm{kg} \text { in the case of } \\
\text { treatment failures) }\end{array}$ & $\begin{array}{l}\text { No experience } \\
\text { in children } \\
\text { below } 6 \text { years }\end{array}$ \\
\hline \multirow[t]{8}{*}{$\begin{array}{l}\text { Soil-transmitted } \\
\text { helminthiases }\end{array}$} & Albendazole & $\begin{array}{l}\text { Chewable } \\
\text { tablet, } 200 \\
\text { and } 400 \mathrm{mg}\end{array}$ & $\begin{array}{l}\text { GlaxoSmithKline, } \\
\text { many generic } \\
\text { producers }\end{array}$ & $\begin{array}{l}400 \mathrm{mg} \text { once for } \\
\text { individuals aged } \\
2 \text { years and above, } \\
\text { single } 200 \mathrm{mg} \text { once } \\
\text { for individuals aged } \\
1-2 \text { years }\end{array}$ & $\begin{array}{l}\text { No experience } \\
\text { in children } \\
\text { below } 1 \text { year }\end{array}$ \\
\hline & & $\begin{array}{l}\text { Suspension, } \\
100 \mathrm{mg} / 5 \mathrm{ml}\end{array}$ & & $\begin{array}{l}20 \mathrm{ml} \text { once for } \\
\text { individuals aged } \\
2 \text { years and above, } \\
10 \mathrm{ml} \text { once for } \\
\text { individuals aged } \\
1-2 \text { years }\end{array}$ & \\
\hline & Mebendazole & $\begin{array}{l}\text { Chewable } \\
\text { tablet, } 100 \\
\text { and } 500 \mathrm{mg}\end{array}$ & $\begin{array}{l}\text { Janssen } \\
\text { Pharmaceutica, } \\
\text { many generic } \\
\text { producers }\end{array}$ & $\begin{array}{l}500 \mathrm{mg} \text { once, } 100 \mathrm{mg} \\
\text { twice a day for } 3 \text { days }\end{array}$ & $\begin{array}{l}\text { No experience } \\
\text { in children } \\
\text { below } 1 \text { year }\end{array}$ \\
\hline & & $\begin{array}{l}\text { Suspension, } \\
100 \mathrm{mg} / 5 \mathrm{ml}\end{array}$ & & $\begin{array}{l}25 \mathrm{ml} \text { once, } 5 \mathrm{ml} \text { twice a } \\
\text { day for } 3 \text { days }\end{array}$ & \\
\hline & Levamisole & $\begin{array}{l}\text { Tablet, } 50 \text { and } \\
150 \mathrm{mg}\end{array}$ & $\begin{array}{l}\text { ICI. } \\
\text { Pharmaceuticals, } \\
\text { many generic } \\
\text { producers }\end{array}$ & $2.5 \mathrm{mg} / \mathrm{kg}$ once & $\begin{array}{l}\text { No experience } \\
\text { in children } \\
\text { below } 1 \text { year }\end{array}$ \\
\hline & & $\begin{array}{l}\text { Suspension, } \\
40 \mathrm{mg} / 5 \mathrm{ml}\end{array}$ & $\begin{array}{l}\text { Generic producers (e. } \\
\text { g. EIPICO) }\end{array}$ & $2.5 \mathrm{mg} / \mathrm{kg}$ once & \\
\hline & Pyrantel pamoate & $\begin{array}{l}\text { Chewable } \\
\text { tablet, } \\
250 \mathrm{mg}\end{array}$ & Pfizer & $\begin{array}{l}10 \mathrm{mg} / \mathrm{kg} \text { once, } 10 \mathrm{mg} / \\
\mathrm{kg} \text { for } 3 \text { days for } \\
\text { individuals aged } 1 \text { year } \\
\text { and above }\end{array}$ & $\begin{array}{l}\text { No experience } \\
\text { in children } \\
\text { below } 1 \text { year }\end{array}$ \\
\hline & & $\begin{array}{l}\text { Suspension, } \\
50 \mathrm{mg} / \mathrm{ml}\end{array}$ & Pfizer & $\begin{array}{l}1 \mathrm{ml} \text { for every } 5 \mathrm{~kg} \\
\text { of body weight }\end{array}$ & \\
\hline \multirow[t]{2}{*}{ Strongyloidiasis } & Ivermectin & $\begin{array}{l}\text { Tablet, } 3 \text { and } \\
6 \mathrm{mg}\end{array}$ & & $\begin{array}{l}200 \mu \mathrm{g} / \mathrm{kg} \text { single dose } \\
15 \mathrm{~kg} \text { and above }\end{array}$ & $\begin{array}{l}\text { Safety and } \\
\text { efficacy in } \\
\text { individuals } \\
\text { weighing less } \\
\text { than } 15 \mathrm{~kg} \\
\text { have not been } \\
\text { established }\end{array}$ \\
\hline & Albendazole & See above & See above & $\begin{array}{l}\text { Multiple doses } \\
\text { (e.g. } 400 \mathrm{mg} \text { twice } \\
\text { daily for } 3 \text { days) ages } \\
2 \text { years and above }\end{array}$ & See above \\
\hline
\end{tabular}

and caretakers has shown that taste was, among twothird of the children, a reason for non-compliance (Milne and Bruss, 2008; Milne, 2009).

\section{Anthelminthic drug formulations}

Table 2 shows the most important anthelminthic drugs currently employed within the frame of preventive chemotherapy programmes, including the most common formulations (WHO, 2006; Hotez et al. 2007). Importantly, these anthelminthics have become the drugs of choice against schistosomiasis, food-borne trematodiases and soil-transmitted helminthiases, the latter including strongyloidiasis. Indeed, millions of people are given one or several of these drugs each year, particularly school-aged 
children (WHO, 2008b, 2010b,c; Fenwick et al. 2009). Manufacturers and recommended dosages, both for adults and the paediatric population are presented. In the remainder of this section we highlight shortcomings linked to drug formulations available for major helminthiases, such as dosing accuracy, lack of PK investigations, unknown bioavailability for extemporaneous preparation and indeed lack of suitable formulations for small children.

\section{Praziquantel}

In $2008,17 \cdot 5$ million individuals were treated with praziquantel in the frame of preventive chemotherapy programmes against schistosomiasis (WHO, 2010b). It is conceivable that several more million people were administered praziquantel, facilitated by local, regional and national control efforts, purchase from pharmaceutical stores, distributed by nongovernmental organisations and aid workers, but these data were not reported to WHO. However, tens of millions of individuals, particularly school-aged children at-risk of schistosomiasis in Africa, still lack access to praziquantel (Utzinger et al. 2009; Hotez et al. 2010; WHO, 2010b). There is a paucity of data regarding the number of people at risk of food-borne trematodiases who have been treated with praziquantel in the frame of preventive chemotherapy.

At present, praziquantel is recommended for individuals aged 4 years and above (WHO, 2002a; Biltricide, package insert). Praziquantel tablets $(600 \mathrm{mg})$ are large, bitter in taste and the recommended dosage for preventive chemotherapy is $40 \mathrm{mg} / \mathrm{kg}$, administered in a single oral dose (Hotez et al. 2007; Meyer et al. 2009). Praziquantel tablets are often split into two or even four parts. However, it has been shown that the weight of split tablets ranges from $50-150 \%$ of the desired weight of the half-tablet weight and even the use of tablet cutters do not improve accuracy (Standing and Tuleu, 2005). Furthermore, although crushing of praziquantel tablets has been recommended by the manufacturer (package leaflet; http://www.merck.com), and indeed employed in recent studies with preschool-aged children infected with schistosomes (Odogwu et al. 2006; Betson et al. 2010; Garba et al. 2010), the bioavailability of the crushed formulation might differ from the original tablet form. To our knowledge, the bioequivalence of praziquantel administered as crushed tablets versus tablets swallowed as a whole remains to be investigated. For example, a recent study, which compared PK parameters of telithromycin administered either as whole tablets or crushed (and offered with nutritional supplement drink) found that both methods of administration were bioequivalent. Hence, crushing of telithromycin could be a viable method of administration for patients unable to swallow whole tablets (Lippert et al. 2005). However, it should be kept in mind that it is difficult to mask the bitter taste of crushed tablets. Infants and children react unfavourably to bitter tastes and the more bitter the drug, the more likely it will be rejected (Mennella and Beauchamp, 2008; Schwartz et al. 2009). Since praziquantel is marketed as racemate, and the antischistosomal activity is stereoselective, new efforts are underway to develop a low-cost chemical synthesis for the active enantiomer, L-praziquantel (Meyer et al. 2009). Of note, L-praziquantel is less bitter than racemic praziquantel (Meyer et al. 2009) and one study in the People's Republic of China reported less adverse events of L-praziquantel compared to the racemate (Wu et al. 1991).

A praziquantel syrup formulation is available (Doenhoff et al. 2009). However, it is not commonly used and not known whether bioequivalence has been thoroughly studied. In addition, it is not known which excipients, which are required for dose uniformity, stability or taste (Standing and Tuleu, 2005) are present. A detailed summary of excipients, their technological function and adverse events has been provided by Pifferi and Restani (2003).

Finally, there is a need to study the safety, doseresponse and $\mathrm{PK}$ of praziquantel thoroughly in children below the age of 4 years, because recent studies in different epidemiological studies documented that schistosomiasis can occur in infants and preschool-aged children, hence well before the age of 4 years (Mafiana et al. 2003; Bosompem et al. 2004; Odogwu et al. 2006; Stothard and Gabrielli, 2007; Betson et al. 2010; Garba et al. 2010; SousaFigueiredo et al. 2010b; Stothard et al. 2011). Preschool-aged children are presently not targeted in schistosomiasis preventive chemotherapy campaigns. However, it has been emphasised that preschool children do not only play a role in local disease transmission, but importantly active infections acquired at early ages might aggravate the clinical significance of the disease in later-life (see Stothard et al. in this special issue). First trials have been carried out, treating preschool children with half or three quarters of a tablet depending on height, using an extended dose pole (Sousa-Figueiredo et al. $2010 a, b)$. However, as highlighted in the present manuscript, a century ago it was recognised by Dr. Jacobi that children and infants are not miniature men and women requiring just reduced doses (Kearns et al. 2003). Rather than using an empirical approach and applying weight-based calculations to the adult dose, there is a need for in-depth studies with praziquantel, including PK, to determine the proper formulations and doses in paediatric patients.

\section{Triclabendazole}

Similar to praziquantel, triclabendazole is currently not registered for use in young children $(<6$ years of age), but off-label use in this age group has been 
reported (WHO, 2007b). Triclabendazole is the current drug of choice against fascioliasis (Keiser et al. 2005; Fairweather, 2009; Keiser and Utzinger, 2010) and we strongly recommend that available data of the safety and efficacy of triclabendazole in preschool-aged children be scrutinized. We anticipate that the evidence-base is currently insufficient, and hence additional clinical trials are warranted to fill existing gaps. Furthermore, an appropriate triclabendazole formulation for young children might be considered. However, it is unlikely that progress in this field will be made in the near future given the fact that fascioliasis is one of the most neglected tropical disease and triclabendazole is currently registered in only four countries (Keiser et al. 2005).

\section{Albendazole, mebendazole, levamisole and pyrantel pamoate}

The main drugs used for the treatment of soiltransmitted helminthiases are albendazole, mebendazole, levamisole and pyrantel pamoate (Bethony et al. 2006; Keiser and Utzinger, 2008). Clearly, the former two-the benzimidazoles albendazole and mebendazole - are the most widely used drugs within the frame of preventive chemotherapy campaigns (WHO, 2006; Hotez et al. 2007). At the moment all four drugs are recommended for children aged 12 months and above. There are currently insufficient data on safety and efficacy for use in younger children which is a problem, as infections are often acquired by infants before they reach 12 months (WHO, 2002a; Montresor et al. 2003). It is interesting to note that for the two widely used benzimidazoles no agespecific dosing regimens exist. For example, a 1 -yearold child (approximately $10 \mathrm{~kg}$ ) receives the same $500 \mathrm{mg}$ mebendazole dose than an $80 \mathrm{~kg}$ adult. Indeed, dosage adaptations based on weight or body surface area (Kearns et al. 2003) have not been suggested for the benzimidazoles in children. To our knowledge PK studies with these drugs have neither been undertaken in infants nor in children. We and others have highlighted that the majority of anthelminthics currently used for preventive chemotherapy have been developed in veterinary parasitology, and hence were not sufficiently optimised for treating human helminth infections (Geary et al. 2010; Keiser and Utzinger, 2010).

Albendazole, mebendazole, levamisole and pyrantel pamoate are available as liquid formulations, which are obviously most appropriate for paediatric patients (Table 2). Typical target dose volumes for paediatric liquid formulations are $<5 \mathrm{ml}$ for children under the age of 5 years and $<10 \mathrm{ml}$ for children aged 5 years and above (European Medicines Agency, 2006). However, the more pleasant the formulation of the medicinal product tastes, the higher the dose volume which will be tolerated by the child. For example, $20 \mathrm{ml}$ of an albendazole suspension are required to achieve a total dose of $400 \mathrm{mg}$. However, in large-scale drug administration programmes liquid formulations of albendazole, mebendazole or levamisole and pyrantel pamoate are rarely used. Albendazole, mebendazole and pyrantel pamoate are also available as chewable tablets. Although the use of chewable tablets is officially recommended for children aged above 6 years, a systematic review on the safety of chewable tablets for children in the US concluded that chewable tablets were a safe and well tolerated alternative to traditional paediatric formulations (Michele et al. 2002). Tragically, in 2007 in Ethiopia four children below the age of 3 years died from choking on chewable albendazole tablets during a deworming campaign (WHO, 2007a). Reasons for the widespread use of tablets in preventive chemotherapy campaigns are the higher cost of the suspension compared to tablets, difficulties of transport and storage due to the larger volume of the liquid formulation, stability issues and the difficulties in handling the liquid formulation. Hence, additional resources for implementation of liquid formulations would be required. Moreover, medication errors commonly occur with liquid formulations. It has been shown, for example that poor dose uniformity is achieved using spoons and dosing cups, hence dropper tubes or syringes are recommended (Breitkreutz and Boos, 2007).

\section{Ivermectin}

Ivermectin, the current drug of choice for strongyloidiasis, is marketed as $3 \mathrm{mg}$ and $6 \mathrm{mg}$ scored tablets. Ivermectin was approved for human use in 1988 and is widely used to control and eliminate filarial infections, usually in combination with albendazole (Fox, 2006; Taylor et al. 2010). Ivermectin is labelled for children weighting more than $15 \mathrm{~kg}$, since the drug might cross the poorly-developed blood brain barrier in infants resulting in possible neurotoxic events (Fox, 2006). There is a need to study the safety of ivermectin in infants in greater detail. In addition, to our knowledge, liquid formulations are not available, hence preschool-aged children, are routinely treated with tablets, which is not the preferred dosage form for this age group (European Medicines Agency, 2006).

\section{IMPLICATIONS FOR CONTROL}

In the mid-1980s, a paradigm shift occurred in the global strategy against schistosomiasis and other major helminth infections; i.e. transmission control was gradually replaced by morbidity control. The advent of safe anthelminthic drugs that showed high efficacy at single oral doses, both in terms of cure rate and egg reduction rate, and hence morbidity 


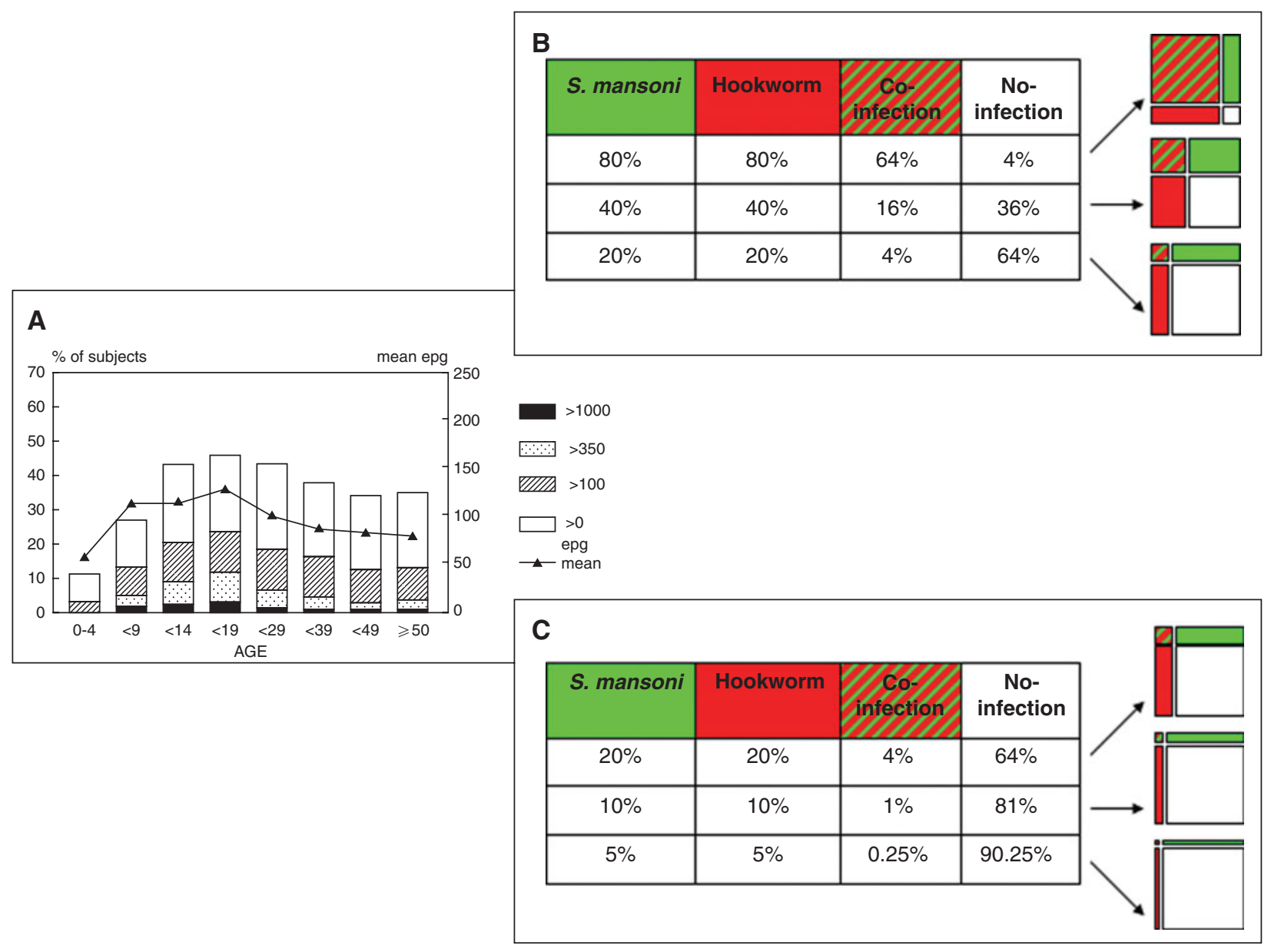

Fig. 6. Conceptual framework summarising the age-prevalence curve of schistosomiasis (a) and hypothetical scenarios of S. mansoni-hookworm co-infection in highly endemic (b) and low endemic (c) settings.

reduction, was at the root of this shift (WHO, 1985). Once the price of anthelminthics plummeted (e.g. terming out of patents or pharmaceutical companies providing anthelminthic drugs free of charge), repeated large-scale administration to at-risk populations became feasible. In May 2001, World Health Assembly (WHA) resolution 54.19 was endorsed, urging member states to regularly treat at least $75 \%$ of school-aged children at risk of schistosomiasis and soil-transmitted helminthiases with praziquantel and albendazole/mebendazole, respectively (WHO, 2002b). Major progress has been made over the past decade and, in 2006, the first African countries reached the $75 \%$ target of administering benzimidazoles to school-aged children at risk of soiltransmitted helminthiasis (WHO, 2008b, 2010c; Savioli et al. 2009).

With regard to schistosomiasis, however, only half a dozen countries in sub-Saharan Africa have (re-) established national schistosomiasis control programmes (Fenwick et al. 2009). Hence only a small fraction of school-aged children at-risk of morbidity due to schistosomiasis are regularly given praziquantel (Hotez et al. 2010; WHO, 2010b). In view of recent reports from different epidemiological settings documenting $S$. haematobium and $S$. mansoni single and even mixed species infections among preschoolaged children (Mafiana et al. 2003; Bosompem et al . 2004; Odogwu et al. 2006; Stothard and Gabrielli, 2007; Betson et al. 2010; Garba et al. 2010; SousaFigueiredo et al. 2010b; Stothard et al. 2011), the question has arisen whether preventive chemotherapy should be extended to this age group.

We welcome this discussion and an informal consultation held at WHO headquarters in Geneva in September 2010. We offer the following points for consideration, with Fig. 6 serving as a conceptual framework. Fig. 6A depicts a typical age-prevalence curve of schistosomiasis, clearly documenting that school-aged children are at highest risk of egg-patent infection and high infection intensity (Jordan and Webbe, 1969). Let us first focus on school-aged children (age: 5-19 years). The mean prevalence in this age group, based on detection of $S$. mansoni eggs in stool samples, is approximately $40 \%$. Concurrently, the egg-patent prevalence of $S$. mansoni in preschool-aged children (age: $0-4$ years) is approximately $10 \%$ or one-fourth of their older counterparts. Of note, immunodiagnostic markers, particularly antigens in urine, can be detected earlier than eggs in stool, and hence the respective prevalence based on antigens might be higher than that determined by egg 
patency (Stothard et al. 2011). Notwithstanding the shortcoming of egg patency at early age, let us assume a similar age-pattern of $S$. mansoni and hookworm infection.

Fig. 6B shows three hypothetical scenarios with school-aged children at risk of a $S$. mansoni infection, a hookworm infection, and a $S$. mansoni-hookworm co-infection. In an epidemiological setting where both infections are highly endemic and no control measures in place, i.e. $80 \%$ of school-aged children infected with either parasite, the likelihood of a coinfection is $64 \%$ under the assumption of random parasite distribution. We argue that such settings are rare to find in contemporary Africa. Suppose that control efforts have been launched and infection prevalences dropped by $50 \%$ for each parasite. The likelihood of a co-infection has now been reduced to $16 \%$. Concurrently, $36 \%$ of the school-aged children are free of both S. mansoni and hookworm infection. Now, let us suppose that preventive chemotherapy is continued and the prevalence of either parasite infection further reduced to $20 \%$ each (Fig. 6C). The likelihood of a co-infection has further dropped to $4 \%$, whereas two-third of the school-aged children are helminth-free. Next, let us focus on preschoolaged children where the prevalence of each parasite is one-fourth of the prevalence in their older counterparts. In the latter setting, less than $1 \%$ of preschool-aged children are co-infected, whereas more than $90 \%$ show no infection at all. Can preventive chemotherapy, using both praziquantel and a benzimidazole, which have yet to be properly tested in children below the age of 4 years, be justified in such a setting? There is a pressing need for additional studies, including risk-benefit analyses. For example, the risk of not treating the preschoolaged population in terms of potential morbidity should be determined and compared to the risk of administering two drugs that lack child-friendly formulations, and detailed information on efficacy, safety and PK in this age group. We conjecture that new research is urgently required to resolve these issues before extension of preventive chemotherapy to preschool-aged children.

\section{CONCLUDING REMARKS AND RESEARCH NEEDS}

Infectious diseases continue to be a leading cause of morbidity and mortality in children, particularly in low-income countries. As we have shown, there is a paucity of studies assessing the safety and efficacy of antiparasitic drugs in children. Moreover, PK investigations and studies in infants and adolescents with antiparasitics are a totally neglected research area. Though sometimes difficult to put into practice, PK studies should also assess the impact of the parasitic infection on the disposition kinetics of the drug, hence ideally be carried out in healthy and diseased children. For example, it has been demonstrated that
PK parameters were altered in patients infected with the liver fluke Opisthorchis viverrini (Na Bangchang et al. 1993). Similarly, in many disease areas no progress has been made with tailored drug formulations for children. Hence, off-label use, empirical dose adaptations and formulation tampering are still the rule rather than the exception.

The forging of new alliances and public-private partnerships between academia, pharmaceutical companies and philanthropic organisations (e.g. Bill \& Melinda Gates Foundation) hold promise to fill the current gaps for optimising current antiparasitic drugs and developing the next generation of antiparasitic drugs (Moran, 2005; Nwaka and Hudson, 2006; Keiser and Utzinger, 2007; Moran et al. 2009). The Medicines for Malaria Venture (MMV) and the Drugs for Neglected Disease initiative $(\mathrm{DND} i)$ can serve as useful role models (see Glossary).

\section{ACKNOWLEDGEMENTS}

We are grateful to Drs. Mark Booth and J. Russell Stothard for their kind invitation to present the current paper at the autumn 2010 symposium, hosted by the British Society for Parasitology (BSP) and co-organised by the Royal Society of Tropical Medicine and Hygiene (RSTMH). Mark and Russ' leadership in putting together this important and enjoyable event, including entertainment at the conference dinner on September 23, 2010, was much appreciated. J. Keiser and K. Ingram acknowledge financial support from the Swiss National Science Foundation (project no. PPOOA-114941) and the Science and Technology Programme Switzerland-Russia.

\section{REFERENCES}

Aponte, J. J., Schellenberg, D., Egan, A., Breckenridge, A., Carneiro, I., Critchley, J., Danquah, I., Dodoo, A., Kobbe, R., Lell, B., May, J., Premji, Z., Sanz, S., Sevene, E., SoulaymaniBecheikh, R., Winstanley, P., Adjei, S., Anemana, S., Chandramohan, D., Issifou, S., Mockenhaupt, F., Owusu-Agyei, S., Greenwood, B., Grobusch, M.P., Kremsner, P. G., Macete, E., Mshinda, H., Newman, R. D., Slutsker, L., Tanner, M., Alonso, P. and Menendez, C. (2009). Efficacy and safety of intermittent preventive treatment with sulfadoxine-pyrimethamine for malaria in African infants: a pooled analysis of six randomised, placebo-controlled trials. Lancet 374, 1533-1542.

Barsch, M. and Otte, A. (2010). The legal standards for the radioactive or non radioactive drugs research and approval in the European Community and in Germany after the thalidomide catastrophe. Hellenic Fournal of Nuclear Medicine 13, 45-51.

Bethony, J., Brooker, S., Albonico, M., Geiger, S. M., Loukas, A. Diemert, D. and Hotez, P. J. (2006). Soil-transmitted helminth infections: ascariasis, trichuriasis, and hookworm. Lancet 367, 1521-1532.

Betson, M., Sousa-Figueiredo, J. C., Rowell, C., Kabatereine, N. B. and Stothard, J. R. (2010). Intestinal schistosomiasis in mothers and young children in Uganda: investigation of field-applicable markers of bowel morbidity. American Fournal of Tropical Medicine and Hygiene 83, 10481055 .

Black, R.E., Cousens, S., Johnson, H. L., Lawn, J. E., Rudan, I., Bassani, D. G., Jha, P., Campbell, H., Fischer Walker, C., Cibulskis, R., Eisele, T., Liu, L., Mathers, C., Child Health Epidemiology Reference Group of WHO and UNICEF (2010). Global, regional, and national causes of child mortality in 2008: a systematic analysis. Lancet 375, 1969-1987.

Boots, I., Sukhai, R. N., Klein, R.H., Holl, R. A., Wit, J. M. Cohen, A. F. and Burggraaf, J. (2007). Stimulation programs for pediatric 
drug research-do children really benefit? European Fournal of Pediatrics 166, 849-855.

Bosompem, K. M., Bentum, I. A., Otchere, J., Anyan, W. K., Brown, C. A., Osada, Y., Takeo, S., Kojima, S. and Ohta, N. (2004). Infant schistosomiasis in Ghana: a survey in an irrigation community. Tropical Medicine and International Health 9, 917-922.

Breitkreutz, J. (2009). Dosage forms for children. After the EU Reform. Pharmazie unserer Zeit 38, 30-37.

Breitkreutz, J. and Boos, J. (2007). Paediatric and geriatric drug delivery. Expert Opinion on Drug Delivery 4, 37-45.

Breitkreutz, J., Tuleu, C. and Solomonidou, D. (2007). Paediatric formulations. In: Guide to Paediatric Clinical Research (ed. Rose, K. and van den Anker, J. N.), pp. 65-77. Karger, Basel.

Choonara, I. (2009). Ethical and safety aspects of clinical trials in neonates. Early Human Development 85, S19-20.

Cohen, J., Dibner, M.S. and Wilson, A. (2010). Development of and access to products for neglected diseases. PLoS One 5, e10610.

Conroy, S., McIntyre, J., Choonara, I. and Stephenson, T. (2000). Drug trials in children: problems and the way forward. British fournal Clinical Pharmacology 49, 93-97.

Doenhoff, M. J., Hagan, P., Cioli, D., Southgate, V., PicaMattoccia, L., Botros, S., Coles, G., Tchuem Tchuenté, L. A., Mbaye, A. and Engels, D. (2009). Praziquantel: its use in control of schistosomiasis in sub-Saharan Africa and current research needs. Parasitology 136, 1825-1835.

European Medicines Agency (2006). Reflection paper: formulations of choice for the paediatric population. European Medicines Agency, London.

Fairweather, I. (2009). Triclabendazole progress report, 2005-2009: an advancement of learning? Fournal of Helminthology 83, 139-150.

Fenwick, A., Webster, J.P., Bosque-Oliva, E., Blair, L., Fleming, F. M., Zhang, Y., Garba, A., Stothard, J. R., Gabrielli, A. F., Clements, A. C. A., Kabatereine, N. B., Toure, S., Dembele, R., Nyandindi, U., Mwansa, J. and Koukounari, A. (2009). The Schistosomiasis Control Initiative (SCI): rationale, development and implementation from 2002-2008. Parasitology 136, 1719-1730.

Fox, L. M. (2006). Ivermectin: uses and impact 20 years on. Current Opinion in Infectious Diseases 19, 588-593.

Garba, A., Barkire, N., Djibo, A., Lamine, M.S., Sofo, B., Gouvras, A. N., Bosque-Oliva, E., Webster, J. P., Stothard, J. R., Utzinger, J. and Fenwick, A. (2010). Schistosomiasis in infants and preschool-aged children: infection in a single Schistosoma haematobium and a mixed $S$. haematobium-S. mansoni foci of Niger. Acta Tropica $\mathbf{1 1 5}$ 212-219

Geary, T. G., Woo, K., McCarthy, J. S., Mackenzie, C. D., Horton, J., Prichard, R. K., de Silva, N. R., Olliaro, P. L., Lazdins-Helds, J. K. Engels, D. A. and Bundy, D. A. (2010). Unresolved issues in anthelmintic pharmacology for helminthiases of humans. International Fournal for Parasitology 40,1-13.

Gosling, R. D., Cairns, M. E., Chico, R. M. and Chandramohan, D. (2010). Intermittent preventive treatment against malaria: an update. Expert Reviews of Anti-Infective Therapy 8, 589-606.

Hotez, P. J., Engels, D., Fenwick, A. and Savioli, L. (2010). Africa is desperate for praziquantel. Lancet 376, 496-498.

Hotez, P. J., Molyneux, D. H., Fenwick, A., Kumaresan, J., Ehrlich Sachs, S., Sachs, J. D. and Savioli, L. (2007). Control of neglected tropical diseases. New England Fournal of Medicine 357, 1018-1027.

Howie, R. C. (2011). Blood sample volumes in child health research: review of safe limits. Bulletin of the World Health Organization 89, 46-53.

Jordan, P. and Webbe, G. (1969). Human Schistosomiasis. William Heinemann Medical Books Ltd, London.

Kastner, M., Wilczynski, N.L., Walker-Dilks, C., McKibbon, K. A. and Haynes, B. (2006). Age-specific search strategies for Medline. Fournal of Medical Internet Research 8, e25.

Kayser, O., Olbrich, C., Croft, S. L, and Kiderlen, A.F. (2003) Formulation and biopharmaceutical issues in the development of drug delivery systems for antiparasitic drugs. Parasitology Research 90 (Suppl. 2), S63-S70.

Kearns, G. L., Abdel-Rahman, S. M., Alander, S. W., Blowey, D. L., Leeder, J.S. and Kauffman, R. E. (2003). Developmental pharmacology-drug disposition, action, and therapy in infants and children. New England Fournal of Medicine 349, 1157-1167.

Keiser, J., Engels, D., Büscher, G. and Utzinger, J. (2005).

Triclabendazole for the treatment of fascioliasis and paragonimiasis. Expert Opinion on Investigational Drugs 14, 1513-1526.

Keiser, J. and Utzinger, J. (2007). Advances in the discovery and development of trematocidal drugs. Expert Opinion on Drug Discovery 2 (Suppl. 1), S9-S23.
Keiser, J. and Utzinger, J. (2008). Efficacy of current drugs against soiltransmitted helminth infections: systematic review and meta-analysis ҰAMA 299, 1937-1948.

Keiser, J. and Utzinger, J. (2010). The drugs we have and the drugs we need against major helminth infections. Advances in Parasitology 73, 197230

Kuepfer, I. and Burri, C. (2009). Reflections on clinical research in subSaharan Africa. International fournal for Parasitology 39, 947-954.

Lippert, C., Gbenado, S., Qiu, C., Lavin, B. and Kovacs, S. J. (2005). The bioequivalence of telithromycin administered orally as crushed tablets versus tablets swallowed whole. Fournal of Clinical Pharmacology 45, 1025-1031

Lunn, P. G. and Northrop-Clewes, C. A. (1993). The impact of gastrointestinal parasites on protein-energy malnutrition in man. Proceedings of the Nutrition Society 52, 101-111

Macleod, S. (2010). Therapeutic drug monitoring in paediatrics: how do children differ? Therapeutic Drug Monitoring 32, 253-256.

Mafiana, C. F., Ekpo, U. F. and Ojo, D. A. (2003). Urinary schistosomiasis in preschool children in settlements around Oyan Reservoir in Ogun State, Nigeria: implications for control. Tropical Medicine and International Health 8, 78-82.

Mellin, G. W. and Katzenstein, M. (1962). The saga of thalidomide Neuropathy to embryopathy, with case reports of congenital anomalies. New England Fournal of Medicine 267, 1238-1244.

Mennella, J. A. and Beauchamp, G. K. (2008). Optimizing oral medications for children. Clinical Therapy 30, 2120-2132.

Meyer, T., Sekljic, H., Fuchs, S., Bothe, H., Schollmeyer, D. and Miculka, C. (2009). Taste, a new incentive to switch to (R)-praziquantel in schistosomiasis treatment. PLoS Neglected Tropical Diseases 3, e357.

Michele, T. M., Knorr, B., Vadas, E. B. and Reiss, T. F. (2002). Safety of chewable tablets for children. Fournal of Asthma 39, 391-403.

Milne, C.P. (2009). Pharmaceutical economics and applications to pediatrics: business case development. In Pediatric Drug Development Concepts and Applications (ed. Mulberg, A. E., Silber, S. A. and van den Anker, J. N.) pp. 39-57. John Wiley \& Sons, Hoboken.

Milne, C.P. and Bruss, J.B. (2008). The economics of paediatric formulation development for off-patent drugs. Clinical Therapy 30, 2133 2145

Montresor, A., Awasthi, S. and Crompton, D.W. T. (2003). Use of benzimidazoles in children younger than 24 months for the treatment of soil-transmitted helminthiasis. Acta Tropica 86, 223-232.

Moran, M. (2005). A breakthrough in R\&D for neglected diseases: new ways to get the drugs we need. PLoS Medicine 2, e302.

Moran, M., Guzman, J., Ropars, A. L., McDonald, A., Jameson, N., Omune, B., Ryan, S. and Wu, L. (2009). Neglected disease research and development: how much are we really spending? PLoS Medicine 6, e30.

Na Bangchang, K., Karbwang, J., Pungpak, S., Radomyos, B. and Bunnag, D. (1993). Pharmacokinetics of praziquantel in patients with opisthorchiasis. Southeast Asian Fournal of Tropical Medicine and Public Health 24, 717-723.

Nor Aripin, K. N. B., Choonara, I. and Sammons, H. M. (2010b). A systematic review of paediatric randomised controlled drug trials published in 2007. Archives of Disease in Childhood 95, 469-473.

Nor Aripin, K. N. B., Sammons, H. M. and Choonara, I. (2010a) Published paediatric randomized drug trials in developing countries, 19962002. Paediatric Drugs 12, 99-103.

Nwaka, S., and Hudson, A. (2006). Innovative lead discovery strategies for tropical diseases. Nature Reviews Drug Discovery 5, 941-955.

Odogwu, S. E., Ramamurthy, N. K., Kabatereine, N. B., Kazibwe, F. Tukahebwa, E., Webster, J.P., Fenwick, A. and Stothard, J. R. (2006). Schistosoma mansoni in infants (aged $<3$ years) along the Ugandan shoreline of Lake Victoria. Annals of Tropical Medicine and Parasitology 100, 315-326

Pandolfini, C. and Bonati, M. (2005). A literature review on off-label drug use in children. European Fournal of Pediatrics 164, 552-558.

Pifferi, G. and Restani, P. (2003). The safety of pharmaceutical excipients. Farmaco 58, 541-550.

Rakhmanina, N. Y. and van den Anker, J. N. (2009). Developmental pharmacology issues: neonates, infants and children. In Pediatric Drug Development Concepts and Applications (ed. Mulberg, A. E., Silber, S. A. and van den Anker, J. N.), pp. 231-242. John Wiley \& Sons, Hoboken.

Rose, K. (2009). European perspective. In Pediatric Drug Development Concepts and Applications (ed. Mulberg, A. E., Silber, S. A. and van den Anker, J. N.), pp. 137-152. John Wiley \& Sons, Hoboken.

Sammons, H. M. and Choonara, I. (2005). Clinical trials of medication in children, 1996-2002. European Fournal of Clinical Pharmacology 61, $165-167$. 
Savioli, L., Gabrielli, A. F., Montresor, A., Chitsulo, L. and Engels, D. (2009). Schistosomiasis control in Africa: 8 years after World Health Assembly Resolution 54·19. Parasitology 136, 1677-1681

Schachter, A. D. and Ramoni, M. F. (2007). Paediatric drug development. Nature Reviews Drug Discovery 6, 429-430.

Schwartz, C., Issanchou, S. and Nicklaus, S. (2009). Developmental changes in the acceptance of the five basic tastes in the first year of life. British Fournal of Nutrition 102, 1375-1385.

Sousa-Figueiredo, J. C., Day, M., Betson, M., Kabatereine, N. B. and Stothard, J.R. (2010a). An inclusive dose pole for treatment of schistosomiasis in infants and preschool children with praziquantel. Transaction of the Royal Society of Tropical Medicine and Hygiene 104, $740-742$.

Sousa-Figueiredo, J.C., Pleasant, J., Day, M., Betson, M., Rollinson, D., Montresor, A., Kazibwe, F., Kabatereine, N. B. and Stothard, J. R. (2010b). Treatment of intestinal schistosomiasis in Ugandan preschool children: best diagnosis, treatment efficacy and side-effects, and an extended praziquantel dosing pole. International Health 2, 103-113.

Standing, J. F. and Tuleu, C. (2005). Paediatric formulations - getting to the heart of the problem. International fournal of Pharmacy 300, 56-66.

Stothard, J. R. and Gabrielli, A. F. (2007). Schistosomiasis in African infants and preschool children: to treat or not to treat? Trends in Parasitology 23, 83-86.

Stothard, J. R., Sousa-Figuereido, J.C., Betson, M., Adriko, M., Arinaitwe, M., Rowell, C., Besiyge, F. and Kabatereine, N. B. (2011). Schistosoma mansoni infections in young children: when are schistosome antigens in urine, eggs in stool and antibodies to eggs first detectable? PLoS Neglected Tropical Diseases 5, e938.

Stötter, H. (2007). Paediatric drug development - historical background of regulatory initiatives. In Guide to Paediatric Clinical Research (ed. Rose, K. and van den Anker, J. N.), pp. 25-32. Karger, Basel.

Strolin Benedetti, M., Whomsley, R. and Baltes, E. L. (2005) Differences in absorption, distribution, metabolism and excretion of xenobiotics between the paediatric and adult populations. Expert Opinion on Drug Metabolism and Toxicology 1, 447-471.

Taylor, M. J., Hoerauf, A. and Bockarie, M. (2010). Lymphatic filariasis and onchocerciasis. Lancet 376, 1175-1185.

United Nations (2009). World Population Prospects: The 2008 Revision. United Nations, Department of Economic and Social Affairs Population Division, New York.

Utzinger, J., Raso, G., Brooker, S., de Savigny, D., Tanner, M., Ørnbjerg, N., Singer, B. H. and N'Goran, E. K. (2009). Schistosomiasis and neglected tropical diseases: towards integrated and sustainable control and a word of caution. Parasitology 136, 1859-1874.

WHO (1985). The control of schistosomiasis: report of a WHO expert committee. WHO Technical Report Series 728, 1-113.

WHO (2002a). Report of the WHO Informal Consultation on the Use of Praziquantel during Pregnancy/Lactation and Albendazole/Mebendazole in Children under 24 Months. World Health Organization, Geneva

WHO (2002b). Prevention and control of schistosomiasis and soiltransmitted helminthiasis: report of a WHO expert committee. WHO Technical Report Series 912, 1-57.

WHO (2006). Preventive Chemotherapy in Human Helminthiasis: Coordinated Use of Anthelminthic Drugs in Control Interventions: A Manual for Health Professionals and Programme Managers. World Health Organization, Geneva.

WHO (2007a). Promoting Safety of Medicines for Children. World Health Organization, Geneva.

WHO (2007b). The Selection and Use of Essential Medicines. World Health Institution, Geneva.

WHO (2008a). The Global Burden of Disease: 2004 Update. World Health Organization, Geneva.

WHO (2008b). Soil-transmitted helminthiasis. Progress report on number of children treated with anthelminthic drugs: an update towards the 2010 global target. Weekly Epidemiological Records 82, 237-252.

WHO (2010a). Working to Overcome the Global Impact of Neglected Tropical Diseases. First WHO Report on Neglected Tropical Diseases. World Health Organization, Geneva.

WHO (2010b). Schistosomiasis. Weekly Epidemiological Records 85, 158-164.
WHO $(2010 c)$. Soil-transmitted helminthiasis. Weekly Epidemiological Records 85, 141-147.

Wu, M. H., Wei, C. C., Xu, Z. Y., Yuan, H. C., Lian, W. N., Yang, Q. J., Chen, M., Jiang, Q. W., Wang, C. Z., Zhang, S. J., Liu, Z. D., Wei, R. M., Yuan, S. J., Hu, L. S. and Wu, Z. S. (1991). Comparison of the therapeutic efficacy and side effects of a single dose of levo-praziquantel with mixed isomer praziquantel in 278 cases of schistosomiasis japonica. American Fournal Tropical Medicine and Hygiene 45, 345-349.

GLOSSARY

ADMET: Absorption, distribution, metabolism, excretion and toxicity

ATC: Anatomical Therapeutical Chemical classification system

BPCA: Best Pharmaceuticals for Children Act (2002)

DALY: Disability-adjusted life year is a composite measure to estimate the burden of disease or injury, expressed as the number of years lost due to illhealth, disability or premature death

DND $i$ : Drugs for Neglected Diseases initiative is a collaborative, not-for-profit drug research and development organisation founded in 2003, based in Geneva, Switzerland that aims to improve the quality of life and the health of people suffering from neglected diseases by using an alternative model to develop drugs for these diseases and by ensuring equitable access to new and field-relevant health tools (http://www.dndi.org/)

FDA: US Food and Drug Administration (http:// www.fda.gov)

FDAMA: FDA Modernization Act (1998)

IPT: Intermittent preventive therapy is a public health intervention aimed at treating and preventing malaria episodes in infants $\left(\mathrm{IPT}_{\mathrm{i}}\right)$, children $\left(\mathrm{IPT}_{\mathrm{c}}\right)$ and pregnant women $\left(\mathrm{IPT}_{\mathrm{p}}\right)$. The intervention builds on two tested malaria control strategies, namely (1) to clear existing parasites (treatment effect seen in mass drug administrations) and (2) to prevent new infections (prophylaxis)

MMV: Medicines for Malaria Venture is a not-forprofit public-private partnership established in 1999, based in Geneva, Switzerland that aims to reduce the burden of malaria in disease-endemic countries by discovering, developing and facilitating delivery of new, effective and affordable antimalarial drugs (http://www.mmv.org/)

Off-label: Use for this population/age class not mentioned in the label

Preventive (anthelminthic) chemotherapy: Use of (anthelminthic) drugs, either alone or in combination, as a public health tool against (helminth) infections 